\title{
Multicomponent nursing program to prevent delirium in critically ill patients: a randomized clinical trial
}

\author{
Programa de enfermería multicomponente para prevención del delirium \\ en pacientes críticamente enfermos: ensayo clínico aleatorizado \\ Programa de enfermagem multicomponente para prevenção de \\ delirium em pacientes críticos: ensaio clínico randomizado
}

How to cite this article: Contreras CCT, Esteban ANP, Parra MD, Romero MKR, Silva CG, Buitrago NPD. Multicomponent nursing program to prevent delirium in critically ill patients: a randomized clinical trial. Rev Gaúcha Enferm. 2021;42:e20200278. doi: https://doi.org/10.1590/19831447.2021.20200278
Universidad de Santander (UDES), School of Health Sciences, Nursing Investigation Group EVEREST. Bucaramanga, Santander, Colombia.

- Universidad de Santander (UDES), School of Health Sciences, Nursing Investigation Group in Public Health. Bucaramanga, Santander, Colombia.

Universidade Federal do Rio Grande do Sul (UFRGS), Escola de Enfermagem, Programa de Pós-Graduaçăo em Enfermagem. Porto Alegre, Rio Grande do Sul, Brasil.

\section{Claudia Consuelo Torres Contreras ${ }^{a}$ Astrid Nathalia Páez Esteban ${ }^{b}$ Myriam Durán Parra ${ }^{a}$ Mayerli Katherine Rincón Romero ${ }^{a}$ Carolina Giordani da Silvac Nohora Paola Duarte Buitrago ${ }^{a}$}

\section{ABSTRACT}

Objectives: To determine the efficacy of a multicomponent nursing program to prevent delirium in critically ill patients.

Methods: Parallel controlled randomized clinical trial to prevent delirium in 81 critically ill patients: 41 in the control group and 40 in the intervention group (intervention: spatial and temporal guidance, visual stimulus, auditive stimulus, and family support). Participants were recruited from September 2017 to March 2018 in the university hospital Los Comuneros, Bucaramanga, Colombia. Clinical Trials record NCT03215745

Results: The incidence of delirium was $5 \%$ in the intervention group and 24\% in the control group. The relative risk was 0.20 (95\% Cl 0.05 to 0.88). The absolute risk reduction was $19.39 \%$ (95\% Cl 4.61 to 34.17) and the number needed to treat was 5 (95 Cl \% 3 to $26 \%$ ).

Conclusion: The multicomponent nursing program is efficient to prevent delirium in critically ill patients.

Keywords: Delirium. Critical care. Primary prevention. Clinical trial. Nursing.

\section{RESUMEN}

Objetivos: Determinar la eficacia de un programa de enfermería multicomponente para la prevención del delirium en pacientes críticamente enfermos

Métodos: Ensayo clínico controlado aleatorizado en paralelo para la prevención de delirium en 81 pacientes críticamente enfermos: 41 en el grupo control y 40 en el grupo intervenido (Intervención: orientación espacial y temporal, estímulo visual, estimulo auditivo y apoyo familiar), reclutados desde septiembre de 2017 a marzo de 2018 en el Hospital Universitario Los Comuneros, Bucaramanga, Colombia. Registro en Clinical Trials número NCT03215745.

Resultados: La incidencia de delirium en el grupo intervenido fue de $5 \%$ y en el grupo control de $24 \%$. Riesgo relativo de 0,20 (IC 95\% 0.05 a 0.88). Reducción absoluta del riesgo 19,39\% (IC95\%4,61 a 34,17) y el número necesario a tratar fue de 5 pacientes (IC95\% 3 a 26\%).

Conclusión: El programa de enfermería multicomponente es eficaz para prevenir el delirium en pacientes críticamente enfermos. Palabras-clave: Delirio. Cuidados críticos. Prevención primaria. Ensayo clínico. Enfermería.

RESUMO

Objetivos: Determinar a eficácia de um programa de enfermagem com multicomponentes para a prevenção de delirium em pacientes críticos.

Métodos: Ensaio clínico controlado randomizado paralelo para prevenção de delirium em 81 pacientes críticos: 41 no grupo controle e 40 no grupo intervenção (Intervenção: orientação espacial e temporal, estimulação visual, estimulação auditiva e apoio familiar), recrutados de setembro de 2017 a março de 2018 no Hospital Universitário Los Comuneros, Bucaramanga, Colômbia. Número de registro de ensaios clínicos é NCT03215745.

Resultados: A incidência de delirium no grupo operado foi de $5 \%$ e no grupo controle de $24 \%$. Risco relativo de 0,20 (IC 95\%0,05 a 0,88). A redução absoluta do risco foi de 19,39\% (IC 95\%4,61 a 34,17) e o número necessário para 0 tratamento foi de 5 pacientes (IC 95\% 3 a 26\%).

Conclusão: 0 programa de enfermagem multicomponente é eficaz na prevenção do delirium em pacientes críticos. Palavras-chave: Delírio. Cuidados intensivos. Prevenção primária. Ensaio clínico. Enfermagem. 


\section{口INTRODUCTION}

Delirium is a serious problem among patients hospitalized in intensive care units (ICUs). It is a transitory organic mental syndrome with an usually sudden, acute, and intermittent outbreak of cognitive disturbances, changes in the level of consciousness, altered attention, increase or diminution in the psychomotor activity, and irregular waking cycles ${ }^{(1-2)}$.

The development of delirium in the intensive care unit threatens the safety of the patients by increasing mortality rates and having a relevant impact on their treatment ${ }^{(3)}$. Its prevalence is of nearly $80 \%$ in adult patients under mechanical ventilation in the ICU, thus influencing directly in hospital costs, leading to a prolonged hospitalization and mortality and generating a cost from 4 to 16 billion dollars a year in the United States alone ${ }^{(1,4)}$.

In the presence of delirium, the brain ages faster, the risk of dementia increases in predisposed individuals, not to mention it can mask previous undiagnosed cognitive degeneration. The main risk factors for delirium are cognitive deteriorations, prior alcohol abuse, and advanced age $(>70$ years old). Dementia is the main risk factor for delirium in the elderly and it generally lasts longer and has more severe symptoms. The most common reversible and independent risk factor for this phenomenon is the polypharmacy. In most cases, it involves sedatives, analgesics, and anticholinergics. Other common risk factors include: severity of the underlying illness, infections, fractures at arrival, and physical restrictions ${ }^{(4)}$.

Furthermore, each day with delirium is independently associated to a $10 \%$ increase in the risk of death. However, the cognitive degeneration can persist for months or years, preventing patients from having their previous quality of life or returning to a previous job $b^{(1,5)}$.

Although delirium has a high prevalence, only $66-84 \%$ of the patients with this complication are diagnosed, due to the fact that, in some circumstances, it can be confused for dementia or anxiety, because there is no adequate diagnostic methodology for its evaluation ${ }^{(6)}$.

As a result, there are recommendations according to which all patients should be evaluated for delirium as they enter the ICU, especially for the stratification of groups with a higher chance of developing $\mathrm{it}^{(3)}$, not to mention factors such as advanced age, primary underlying brain illnesses, chronic illnesses, pharmacological agents, and environmental factors that predispose to their appearance ${ }^{(6-8)}$.
Therefore, the diagnosis, as well as the implementation of treatment and preventive interventions for delirium in patients at risk, requires all health workers involved in ICU health care to collaborate. Nurses, due to their almost constant contact with their patients, are the most adequate to detect delirium early; however, they do not carry out adequate evaluations in their daily practices ${ }^{(3)}$. The potential hindrances for an evaluation of delirium are: (1) complex or unused assessment tools; (2) lack of knowledge about delirium; (3) difficulties in the evaluation of intubated or sedated patients; and (4) time restrictions ${ }^{(3,8)}$.

The use of related guidelines and protocols in the diagnosis, management, and prevention of delirium can help nurses. There are guidelines available that focus on the prevention of delirium in people identified as being under risk, using a directed non-pharmacological intervention with multiple components, that addresses a series of modifiable risk factors ${ }^{(3)}$. On the other hand, since it is preventable, it can be seen as an indicator of quality in health institutions.

This would be characterized as a multicomponent nursing intervention because it includes the mediation of some risk factors to develop delirium in the intensive care units. Also, it can be carried out by nursing personnel independently, since the strategies are feasible in the current context of care. Measures such as time, space, and person orientation, aiding the patient with visual and auditive stimuli and with family support lead to consistent benefits in the evolution of their framework. Furthermore, these are cost-effective actions to prevent delirium and diminish its severity and duration ${ }^{(9)}$.

Thus, the multicomponent program to prevent delirium includes individualized non-pharmacological interventions, such as multi-sensory stimulation, cognitive activation and stimulation, and activation of functional and family participation ${ }^{(6)}$. However, there are no conclusive studies on the theme, and non-pharmacological interventions to prevent delirium in critical patients have never been proven effective. Although few studies focused on the exploration of relevant factors and on the development of strategies to prevent delirium, the evidence is still scarce, and needs to be further developed in regard to non-pharmacological measures that can be used for nurses, considering the severity and the irreversible effects of delirium on the short and large terms in critically ill patients.

This multicomponent non-pharmacological intervention is focused on the 4 risk factors for delirium, through 
cognitive stimuli, reality reorientation, time and space orientation, auditory and visual stimuli, the use of didactic material and photographs, drawings, and family support, the latter being an important protective factor for the prevention of delirium.

As a result, the objective of this study was to determine the efficacy of a multicomponent nursing program to prevent delirium in critically ill patients. The hypothesis of the study was that this program diminishes the incidence of delirium in critically ill patients.

\section{METHOD}

\section{Design of the study}

This study carried out a parallel, controlled, double-blind randomized clinical trial to evaluate the efficacy of a multicomponent nursing program to prevent delirium in critically ill patients recruited from September 2017 to March 2018. It was developed by the Universidad de Santander and by the university hospital Los Comuneros, in Bucaramanga, Colombia. The protocol was registered at Clinical Trials under protocol NCT03215745.

\section{Population}

The research included critically ill patients above 18 years old who had been for 24 hours in a multipurpose intensive care unit that attends surgical patients and those with different medical pathologies in 39 intensive care beds. Inclusion criteria: persons with vasoactive support, invasive or non-invasive mechanical ventilation and invasive monitoring, Richmond Agitation and Sedation Scale (RASS) from -3 to +4 , with no delirium at admittance and a predicted $40 \%$ or higher chance of delirium according to the PRE-DELIRIC model ${ }^{(10)}$. Participants with cognitive deficits, previous mental disorders, and history of delirium and alcoholism were excluded.

\section{Sample size}

The sample size was calculated using the G Power based on a level of reliability of $95 \%$, a power of $80 \%$, a reason of $1: 1$, and a relative risk of 0.17 . The total sample size was of 80 patients, 40 in the intervention group and 40 in the control group.

\section{Randomization and blinding}

The randomization was carried out in blocks of 4 patients through a sequence generated by computer at the website www.randomization.com. In addition, a person who was not part of the group of researchers managed the list of patients. The evaluator and the analyst of data were both blinded for the intervention. It was not possible to blind the patient due to the nature of the intervention.

\section{Data collection}

Patients were recruited 24 hours after their arrival at the ICU. The criteria of inclusion were verified, and the patient was evaluated and randomly assigned to either the control or intervention group. They were monitored daily using the Confusion Assessment Method for Intensive Care Units (CAM-ICU) until the patient left the ICU, presented delirium, or passed away. Chart 1 shows the activities carried out in the intervention and control groups, and the daily monitoring.

\section{Event}

The main event was delirium, which was evaluated using the CAM-ICU scale, which considers 4 criteria: acute and intermittent start, lack of attention, disorganized thoughts, and altered level of consciousness. The delirium was evaluated as such if the reaction level of the patient according to the RASS was above -3. To diagnose delirium, two greater criteria are necessary (acute or intermittent start and lack of attention), and at least one of the better criteria (disorganized thoughts and altered level of consciousness). This method establishes the diagnosis of delirium according to the Diagnositc and Statistical Manual of Mental Disorders ${ }^{(2)}$.

\section{Variables}

Adicionalmente, se evaluaron las siguientes variables: Sexo, edad, servicio de origen, grupo de diagnóstico médico, admisión o ingreso urgente, uso de morfina, uso de sedantes, infección, acidosis metabólica, ventilación mecánica, puntaje APACHE II, días estancia hospitalaria, coma y puntaje de predicción de delirium a través del modelo PRE-DELERIC ${ }^{(10)}$.

\section{Statistical analysis}

The data was inserted in EPIDATA through double entry and validated. The analysis was carried out using Stata 14. The distribution of quantitative variables was evaluated using the Shapiro-Wilk test. The mean was calculated, as well as the standard deviation, for the normal variables. The median with an interquartile range was used otherwise. The proportion of qualitative variables were calculated and compared between the groups using $X^{2}$ or Fisher's exact tests. An intention-to-treat 


\begin{tabular}{|c|c|}
\hline $\begin{array}{l}\text { Control group } \\
(n=41)\end{array}$ & Intervention group $(n=40)$ \\
\hline $\begin{array}{l}\text { The control group } \\
\text { received regular care, } \\
\text { which consisted in } \\
\text { standard hospital } \\
\text { care: orientation } \\
\text { and diminution of } \\
\text { environmental stimuli, } \\
\text { such as noise and } \\
\text { lighting. } \\
\text { This care was } \\
\text { provided by general } \\
\text { practitioners, } \\
\text { specialized physicians, } \\
\text { nurses, and } \\
\text { support personnel. } \\
\text { The members of the } \\
\text { intervention team did } \\
\text { not provide services to } \\
\text { the patients who were } \\
\text { in the control group } \\
\text { and thus received } \\
\text { regular care. } \\
\text { However, the same } \\
\text { group of physicians } \\
\text { and specialists, } \\
\text { nurses and support } \\
\text { personnel, and the } \\
\text { resident physicians } \\
\text { provided regular } \\
\text { care to both groups. }\end{array}$ & $\begin{array}{l}\text { The intervention group was also treated with the multicomponent nursing program. } \\
\text { For the interventions, a calm and private environment was formed by closing the device to } \\
\text { enter the cubicle (doors, curtains), thus providing privacy. } \\
\text { Two previously trained nurses carried out the intervention daily, starting when the patient } \\
\text { entered the study and ending when they left it. The intervention lasted for nearly } 15 \\
\text { minutes. Below, there is a description of the activities carried out: } \\
\text { COGNITIVE STIMULATION } \\
\text {-Time and space orientation: At first, the patient was daily complimented, called by their } \\
\text { name, and was offered information about the space, with their location and why they were } \\
\text { there. } \\
\text { Later, a watch and a calendar were shown to the patient. Then, there was a conversation } \\
\text { about the events and news, to encourage and stimulate the person. } \\
\text { Discussions and an active listening were encouraged: the patient was asked about prior } \\
\text { experiences, current activities, and there were attempts to connect the past and the } \\
\text { present. Also, games of word search and crosswords were also made available. } \\
\text { - Visual and auditory stimuli: direct visual contact, frequent use of contact, the use of visual } \\
\text { and auditory devices (glasses, hearing aids), active listening to the patient, allowing them to } \\
\text { manifest their preoccupations and respond to questions. During contact with the patient, } \\
\text { the voice was low, the tone of voice was medium, and the sentences were short and clear. } \\
\text { The communication was concrete and specific. } \\
\text { Photographs, letters, and drawings from magazines or made by their relatives were shown. } \\
\text { They were asked about what personal items they would like to have at hand during their } \\
\text { stay at the hospital, and they were helped to get these items. These could include: glasses, } \\
\text { hearing aids, dental prosthesis, family photos, religious objects. } \\
\text { The use of matching games such as: marking from a list the objects that belong inside } \\
\text { a fridge. } \\
\text { FAMILY supPORT } \\
\text { The inclusion of family and caregivers in the self-care and in the reorientation of the patient } \\
\text { was encouraged. } \\
\text { Education was provided about delirium and its complications. It was made easier for a } \\
\text { relative or person of confidence of the patient to get closer and stay as long as possible. }\end{array}$ \\
\hline \multicolumn{2}{|c|}{$\begin{array}{l}\text { Daily follow up using CAM-ICU and RASS: the intervention was carried out daily and the CAM-ICU scale was used } \\
\text { to verify the effect of the intervention (whether or not delirium was developing). If the health state of the patient } \\
\text { worsened or their sedation level did not allow for the intervention to be carried out, the intervention was resumed } \\
\text { when the conditions needed to continue the activities of preventing delirium were present again. This was done } \\
\text { within a limit of } 8 \text { days, that is, any patient who had still not recovered after this period was removed from the study. }\end{array}$} \\
\hline
\end{tabular}

Chart 1 - Description of the multicomponent nursing intervention and of the control group care Source:The authors, 2020.

analysis was carried out, and the incidence of delirium was calculated for both the control and intervention groups. The relative risk, with a 95\% confidence interval, the absolute risk reduction, and later, the number needed to treat (NNT) as a measure of impact, were also calculated. Furthermore, the accumulated hazard was calculated and graphed in groups according to the Kaplan-Meier method to visualize the effect of the intervention. Finally, the hazard ratio (HR) was calculated. 


\section{Ethical aspects}

The investigation was carried out following the prescriptions of resolution 8430 from 1994 in Colombia and was approved by the research ethics committee of the Universidad Santander (Acta 012-14) and from the university hospital Los Comuneros. Written informed consent was provided by the patient or by a proxy when the patient was incapable of doing so.

\section{RESULTS}

The study was developed and reported according to the CONSORT guidelines for clinical trials with non-pharmacological interventions ${ }^{(11)}$. Figure 1 shows the flowchart of patients according to the CONSORT.

81 patients were randomized, monitored, and analyzed, 41 in the control group and 40 in the intervention group, as per Figure 1. In the control group there were 4 deaths, and,

\section{Recruitment}

Evaluated for eligibility

$(n=110)$

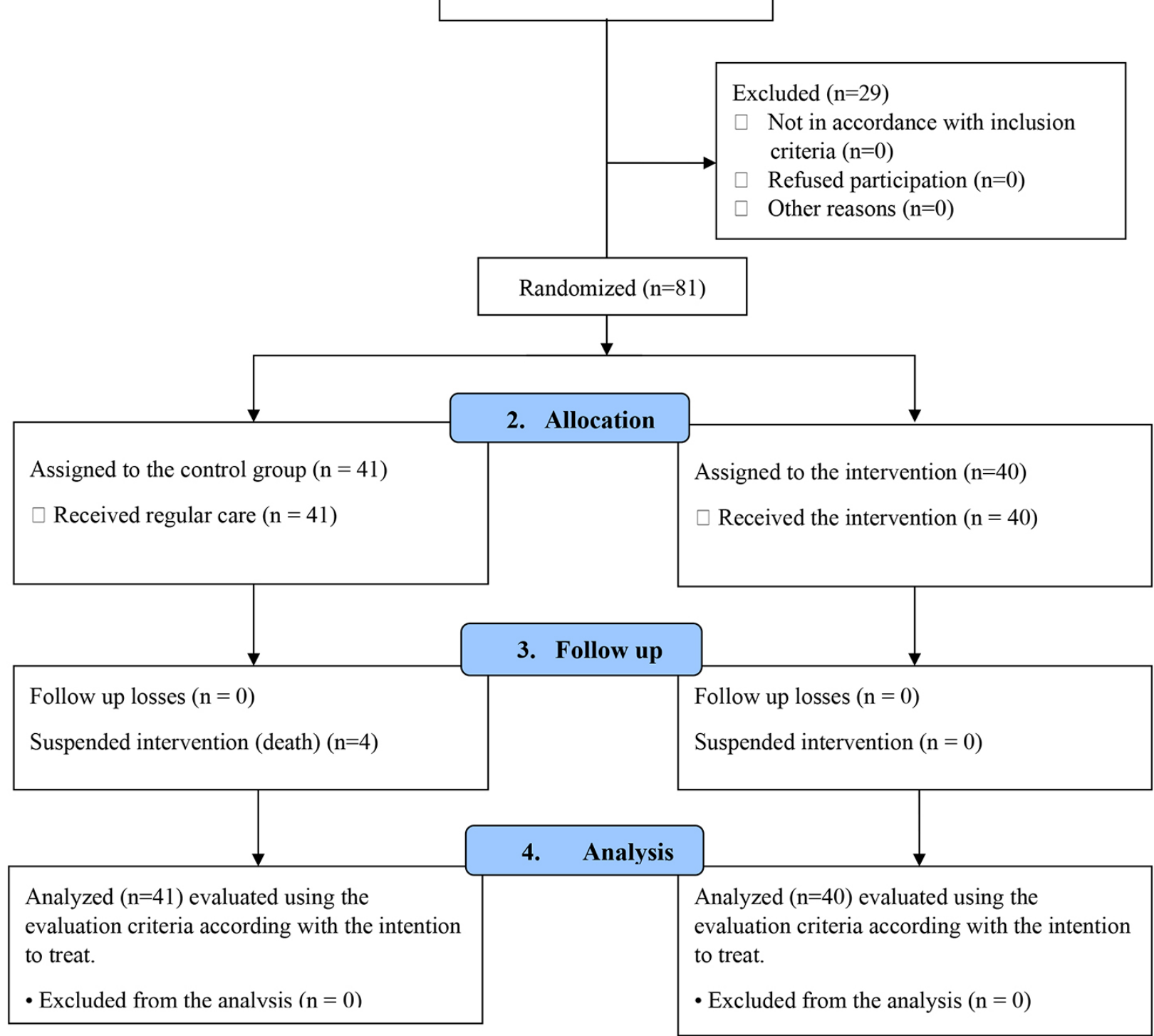

Figure 1 - Flowchart with the results of the selection Source: the authors (2020) 
as a result, the number of critical patients at the end of the study was 37 in the control group and 40 in the intervention group. However, the results of the 81 randomized patients are presented here, because the analysis was carried out according to the intention to treat, as recorded in the protocol, considering a conservative setting in the findings and having as a criterion of quality the evaluation of the validity of the clinical trials. The base characteristics in the groups were balanced as observed in Table 1.

The incidence of delirium was $5 \%$ in the intervention group and $24 \%$ in the control group. As a result, the relative risk was 0.20 with a $95 \% \mathrm{Cl}$ from 0.05 to 0.88 . The absolute difference of the risk was $19.39 \%$ with a $95 \%$ Cl from 4.61 to 34.17 and the NNT was 5 critical patients with 95\% Cl from

Table 1 - Characterization of critically ill patients from the control and intervention groups, Bucaramanga, Colombia $2017-2018$

\begin{tabular}{|c|c|c|c|c|c|}
\hline \multirow[t]{2}{*}{ Variable } & \multicolumn{2}{|c|}{$\begin{array}{c}\text { Control } \\
n=41\end{array}$} & \multicolumn{2}{|c|}{$\begin{array}{l}\text { Intervention } \\
\qquad n=40\end{array}$} & \multirow{2}{*}{ P value* } \\
\hline & $\mathbf{N}$ & $\%$ & $\mathbf{N}$ & $\%$ & \\
\hline Sex Male & 26 & 63.4 & 25 & 62.5 & 0.93 \\
\hline Age $\geq 60$ years & 33 & 80.5 & 32 & 80 & 0.96 \\
\hline \multicolumn{6}{|l|}{ Origin } \\
\hline Emergency & 26 & 63.4 & 19 & 47.5 & \multirow[t]{4}{*}{0.50} \\
\hline Surgery & 1 & 2.4 & 4 & 10.0 & \\
\hline Hospitalization & 4 & 9.8 & 6 & 15.0 & \\
\hline External & 10 & 24.4 & 11 & 27.5 & \\
\hline \multicolumn{6}{|l|}{ Diagnostic group } \\
\hline Medical & 34 & 82.9 & 26 & 65.0 & \multirow[t]{4}{*}{0.17} \\
\hline Surgical & 0 & 0.0 & 3 & 7.5 & \\
\hline Trauma & 1 & 2.4 & 2 & 5.0 & \\
\hline Neurology/neurosurgery & 6 & 14.6 & 9 & 22.5 & \\
\hline Urgent admission & 41 & 100.0 & 36 & 90.0 & 0.07 \\
\hline Morphine use & 11 & 26.8 & 10 & 25 & 0.85 \\
\hline Sedative use & 23 & 56.1 & 22 & 55 & 0.92 \\
\hline Infection & 27 & 65.9 & 24 & 60 & 0.59 \\
\hline Metabolic acidosis & 7 & 17.1 & 13 & 32.5 & 0.11 \\
\hline Mechanical ventilation & 17 & 41.5 & 21 & 52.5 & 0.32 \\
\hline APACHE II >14 & 38 & 92.7 & 40 & 100 & 0.08 \\
\hline Hospital stay $\geq 5$ days & 29 & 70.7 & 27 & 67.5 & 0.75 \\
\hline Coma & 6 & 14.6 & 11 & 27.5 & 0.15 \\
\hline PREDELIRIC > 50 & 32 & 78.0 & 35 & 87.5 & 0.26 \\
\hline
\end{tabular}

Source: data from the investigation, 2018

*Chi-squared Fisher's exact tests. 
3 to $26 \%$, as in Table 2. Similarly, the rate of incidence of delirium in the control group was 42.37 per 1000 person/days, 95\% Cl 22.80 to 78.75 , while in the intervention group it was 7.87 per 1000 person/days $95 \%$ Cl 1.97 to 31.48 , to a hazard ratio of $0.1995 \% \mathrm{Cl} 0.04$ to 0.90, as observed in Figure 2.
The $\mathrm{p}$ value resulting from the proportionality test of the incidence rates was 0.24 .

Furthermore, the number of deaths in the control group was 4 (9.75\%) and there were none in the intervention group, with a $p$ value of 0.04

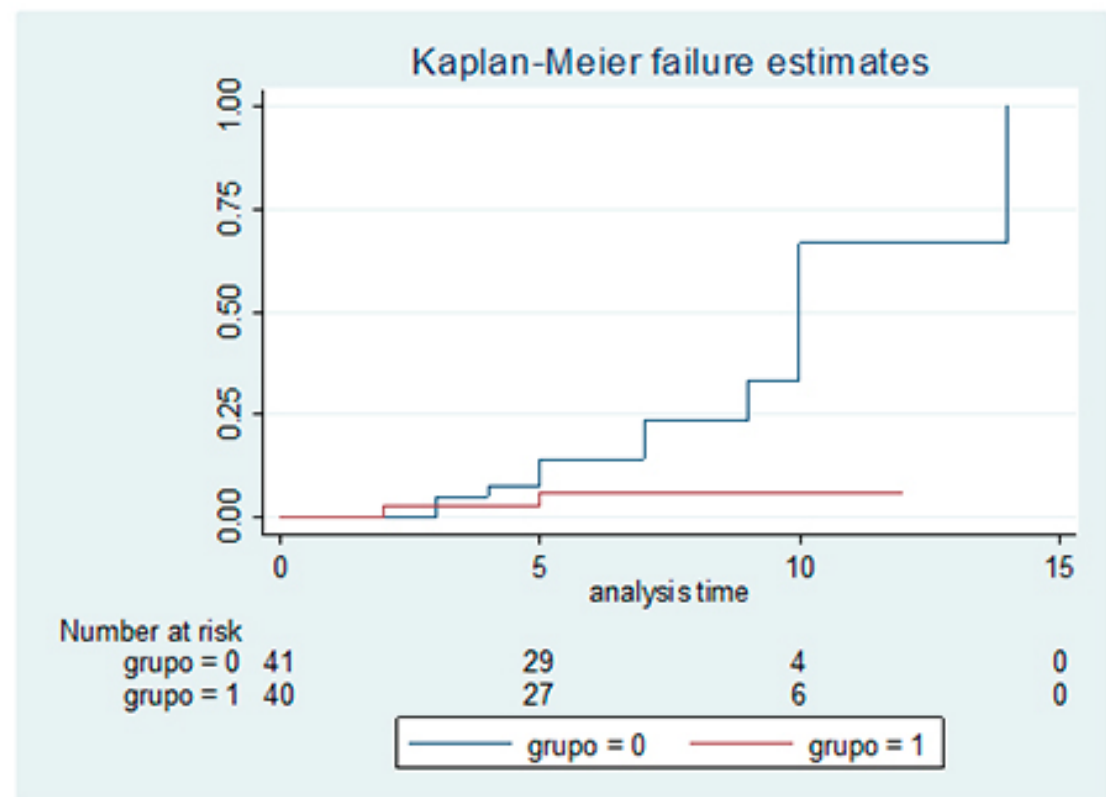

Figure 2 - Accumulated risk for delirium in critically ill patients from the control and intervention groups, Bucaramanga Colombia 2017-2018

Source: data from the investigation, 2018.

Table 2 - Effect and impact measures of the multicomponent nursing program in critically ill patients. Bucaramanga, Colombia 2017-2018

\begin{tabular}{|c|c|c|c|}
\hline \multirow{2}{*}{ Category } & $\begin{array}{c}\text { Control } \\
n=41\end{array}$ & $\begin{array}{l}\text { Intervention } \\
\qquad n=40\end{array}$ & \multirow{2}{*}{ Measurement } \\
\hline & n \% & $n \%$ & \\
\hline Delirium & $10(24.4)$ & $2(5.0)$ & $0.01^{*}$ \\
\hline $\mathrm{RR}(95 \% \mathrm{Cl})$ & & & 0.20 (0.05 to 0.88$)$ \\
\hline $\operatorname{ARR}(95 \% \mathrm{Cl})$ & & & $19.39(4.61$ to 34.17$)$ \\
\hline NNT (95\% Cl) & & & 5 (3 to 26$)$ \\
\hline
\end{tabular}

Source: data from the investigation, 2018

*P value. RR: relative risk. ARR: absolute risk reduction NNT: number needed to treat $\mathrm{Cl}$ : confidence interval 


\section{DISCUSSION}

The analysis of the results showed that the application of the multicomponent nursing program used in this study, which includes cognitive stimulation interventions with time and space orientation, auditory and visual stimuli and family support (as detailed in Chart 1), was efficient to prevent delirium in critically ill patients admitted in an intensive care unit, according to the data in Table 2, with an incidence of 2 cases of delirium in the intervention group and 10 cases in the control group (RR 0.20; 95\% Cl: 0.05 to $0.88, \mathrm{p}<0.01$ ). This data is coherent with a systematic review and meta-analysis of 11 studies that included 12 unique interventions, showing that the non-pharmacological multicomponent interventions, such as time and space orientation, auditory and visual stimulation, and family support are highly effective to reduce the occurrence of delirium (OR 0.47; Cl 95\%: 0.38 to 0.58 ) and falls (OR $0.38 ; 95 \% \mathrm{Cl}: 0.25$ to 0.60 ) during the hospitalization of individuals in critical condition ${ }^{(12)}$.

Furthermore, the same revision states that, approximately, 1 million cases of delirium in the hospitals could be avoided every year using non-pharmacological multicomponent interventions. This would lead to the saving of approximately US\$10,000 per case, or US\$ 10 billion per year in the United States ${ }^{(12)}$, showing the importance of studies that evaluate non-pharmacological nursing interventions to prevent and reduce the incidence of delirium in this context.

To this end, the non-pharmacological focus has been the most used strategy among nurses to prevent delirium ${ }^{(13)}$. A set of non-pharmacological interventions known as the Hospital Elder Life Program - HELP -, which is targeted at the control of cognitive deterioration through the use of clocks, calendars, graphic indications of the hour of day, and language interprets; familiarity interventions, with objects and family members; the maintenance of sleep, through the control of noise and bright lights. The use of the bright light therapy to establish a healthy sleep-wake cycle with the adequate time to effectively correct the altered circadian cycle from the wake stage to the desired one. In elder patients with the advanced sleep phase syndrome (ASPS), it has been found that daily exposure to intense light during the day can be beneficial. This can be done by using a bright light box of 1000-3000lux or by spending time under external sunlight, 1-2 hours a day in the morning and in the afternoon ${ }^{(14)}$. Movement early in the day, with physical therapy; visual and auditory support, with eye contact, empathy, talking calmly, and hydration were all found to have effects on the incidence of the number of days with delirium(4).

There is a successful strategy for a fast and pronounced reduction in the severity of delirium that combines orientation interventions using clock, calendar, a graph with the time of the day, visual and auditory aids, and language interprets; familiarity interventions using objects and family members; physical therapy and a restricted use of neuroleptics. This strategy is in line with the data from this clinical trial, and also cooperates to cognitive improvement after discharge ${ }^{(4,15)}$.

Another multicomponent intervention used in this study was the use of the strategy of bringing news from the radio and current data to the patients, thus helping them to orient themselves in time and space. This was associated with the familiarity interventions, the presence of known objects and people and the use of communication with visual contact, including empathy and calm speaking patterns. The strategy that included all of the above was associated with a faster cognitive improvement, corroborating the findings of studies that indicated that the use of these non-pharmacological interventions was efficient to prevent the incidence of delirium in the intensive care units, especially in elderly patients ${ }^{(12-13)}$.

Another therapeutic method used in the set of multicomponent interventions was the support of the family members in the context of attention, thus positively contributing for the guidance of the patient and the prevention of delirium. The studies indicate that, in the context of the ICU, the members of the family could undoubtedly have an important role in the prevention and reduction of the development of the symptoms of delirium, establishing formal partnerships with the nursing team, since they are usually not integrated in the practice ${ }^{(16-18)}$.

The benefits of the presence of the relative is associated to the fact that the patient recognizes the voice of a family member, which brings them closer to their daily routine, in addition to helping them feel calm and comfortable. This benefit also extends to the members of the family, who feel more useful while they remain physically and emotionally near the patient. It also shows that, when they participate, the families seem to perceive the nursing personnel as more respectful, supportive, and collaborative. Therefore, these and other multicomponent non-pharmacological nursing interventions carried out in the patients in intensive care units show the need to continue working in strategies that can promote the quality of care practices, making nursing work more visible ${ }^{(18-19)}$.

Considering the above, the effect of the multicomponent nursing program in the prevention of delirium is evident, since it can be done daily and easily in the ICU with no additional risks to the patient. However, it should be noted that the number needed to treat in this intervention was of 5 critically ill patients ( $95 \% \mathrm{Cl}: 3-26)$, lower than the one found in a systematic review $(14.3,95 \% \mathrm{Cl}: 11.1-20.0)^{(13)}$. 
Although the data above shows that the multicomponent nursing program is effective to prevent against delirium, it is impossible to determine the effectiveness of each component individually, since, to determine that, it would be necessary to apply and measure each one separately. This is a limitation of this study. Another limitation is the reduced number of delirium cases in each group, although the number was enough to find statistically significant differences between them.

On the other hand, despite the importance of using a non-pharmacological multicomponent intervention program to prevent delirium, this does not make nursing evaluation unnecessary to determine which interventions should be used to care for the singular needs of each patient receiving attention, thus guaranteeing an efficient care.

\section{CONCLUSION}

The non-pharmacological multicomponent nursing program diminished the absolute incidence of delirium in $19 \%$ in critically ill patients, confirming the hypothesis of the study, which showed the efficacy of the multicomponent intervention when compared to the standard care to manage this condition.

Among the strengths of this study are the rigorous training of the work team to evaluate delirium and its strict daily follow up, which took place even on Sundays or holidays, thus avoiding any losses of the data of patients included. Similarly, the random allocation of patients made it possible for the groups to be homogeneous, that is, with comparable basal characteristics. This made it easier to evaluate the efficacy of the intervention proposed. Furthermore, an intention-to-treat analysis was carried out, which is the most conservative estimation of the effect of the intervention.

The limitations of this study are the fact that these non-pharmacological interventions to prevent delirium were applied together, involving many domains. As a result, it is impossible to determine the effectiveness of each therapeutic action individually. Furthermore, the effectiveness of the interventions to control the symptoms of delirium was not evaluated.

These findings are expected to contribute to a nursing care that is less invasive and more effective in the prevention of delirium in critically ill patients in the ICU, thus qualifying the care provided to these patients. Furthermore, they can also promote learning and the implementation of these interventions in nursing workers of intensive care units, as well as encourage new investigations about the theme, complementing the findings of this study and, therefore, contributing to the formation of knowledge in this subject.

\section{REFERENCES}

1. Cai S, Minzhi LV, Latour JM, Lin Y, Pan W, Zheng J, et al. Incidence and risk factors of PostopeRativE delirium in intensive care unit patients: a study protocol for the PREDICt study. J Adv Nurs. 2019;75(11):3068-77. doi: https://doi.org/10.1111/ jan.14097

2. American Psychiatric Association. Diagnostic and statistical manual of mental disorders (DSM-5). 5th ed. Washington DC: American Psychiatric Pub Inc; 2013.

3. Özsaban A, Acaroglu R. Delirium assessment in ICU: practices and perceptions of Turkish nurses. Nurs Crit Care. 2016;21(5):271-8. doi: https://doi.org/10.1111/ nicc. 12127

4. Cerveira CCT, Pupo CC, Santos SDS, Santos JEM. Delirium in the elderly: a systematic review of pharmacological and non-pharmacological treatments. Dement Neuropsychol. 2017;11(3):270-5. doi: https://doi. org/10.1590/1980-57642016dn11-030009

5. Norman BC, Jackson JC, Graves JA, Girard TD, Pandharipande PP, Brummel NE, et al. Employment outcomes after critical illness: an analysis of the bringing to light the risk factors and incidence of neuropsychological dysfunction in ICU survivors cohort. Crit Care Med. 2016; 44(11):2003-9. doi: https://doi.org/10.1097/ cCM.0000000000001849

6. Torres-Contreras CC, Páez-Esteban AN, Hinestrosa-Díaz Del Castillo A, Rincón-Romero MK, Amaris-Vega A, Martínez-Patiño JP. Factors associated with delirium in critical patients in a health institution in Bucaramanga, Colombia. Enferm Intensiva. 2019;30(1):13-20. doi: https://doi.org/10.1016/j. enfi.2018.03.002

7. Axell GA, Bergbom I. Intensive care unit delirium, clinical observations, and patients' statements: a case study. Dimens Crit Care Nurs. 2020;39(4):169-79. doi: https://doi.org/10.1097/DCC.0000000000000424

8. Bohart S, Møller AM, Herling, S. Do health care professionals worry about delirium? relatives' experience of delirium in the intensive care unit: a qualitative interview study. Intensive Crit Care Nurs. 2019;53:84-91. doi: https://doi.org/10.1016/j. iccn.2019.04.010

9. Eberle CC, Santos AA, Macedo Júnior LJJ. Non-pharmacological management of delirium from the perspective of nurses in na adult intensive care unit. Rev Pesq: Cuid Fundam online. 2019;11(5):1242-9. doi: https://doi.org/10.9789/21755361.2019.v11i5.1242-1249

10. Wassenaar A, Schoonhoven L, Devlin JW, van Haren FMP, Slooter AJC, Jorens PG, et al. External validation of two models to predict delirium in critically ill adults using either the Confusion Assessment Method-ICU or the Intensive Care Delirium Screening Checklist for delirium assessment. Crit Care Med. 2019;47(10):e827-35. doi: https://doi.org/10.1097/CCM.0000000000003911

11. Boutron I, Altman DG, Moher D, Kenneth F, Philippe R. CONSORT statement for randomized trials of nonpharmacologic treatments: a 2017 update and a CONSORT extension for nonpharmacologic trial abstracts. Ann Intern Med. 2017;167(1):40-7. doi: https://doi.org/10.7326/M17-0046

12. Hshieh TT, Yue J, Oh E, Puelle M, Dowal S, Travison T, et al. Effectiveness of multicomponent nonpharmacological delirium interventions: a meta-analysis. JAMA Intern Med. 2015;175(4):512-20. doi: https://doi.org/10.1001/ jamainternmed.2014.7779 
13. Inouye SK, Westendorp RG, Saczynski JS. Delirium in elderly people. Lancet. 2014;383(9920):911-22. doi:https://doi.org/10.1016/S0140-6736(13)60688-1

14. Bai J, Liang Y, Zhang P, Liang X, He J, Wang J, et al. Association between postoperative delirium and mortality in elderly patients undergoing hip fractures surgery: a meta-analysis. Osteoporos In. 2020;31(2):317-26. doi: https://doi. org/10.1007/s00198-019-05172-7

15. Yang Z, Wang XF, Yang LF, Fang C, Gu XK, Guo HW. Prevalence and risk factors for postoperative delirium in patients with colorectal carcinoma: a systematic review and meta-analysis. Int J Colorectal Dis. 2020;35(3):547-57. doi: https:// doi.org/10.1007/s00384-020-03505-1

16. Bautista Rodríguez LM, Arias Velandia MF, Carreño Leiva ZO. Percepción de los familiares de pacientes críticos hospitalizados respecto a la comunicación y apoyo emocional. Rev Cuid. 2016;7(2):1297-309. doi: https://doi.org/10.15649/cuidarte.v7i2.330
17. Martinez F, Tobar C, Hill N. Preventing delirium: should non-pharmacological, multicomponent interventions be used? a systematic review and meta-analysis of the literature. Age Ageing. 2015;44(2):196-204. doi: https://doi.org/10.1093/ ageing/afu173

18. Mitchell ML, Kean S, Rattray JE, Hull AM, Davis C, Murfield JE, et al. Family intervention to reduce delirium in hospitalized ICU patients: a feasibility randomized controlled trial. Intensive Crit Care Nurs. 2017;40:77-84. doi: https:// doi.org/10.1016/j.iccn.2017.01.001

19. Barros FRB. Adesão ao bundle de prevenção de pneumonia associada à ventilação mecânica. Rev Cuid. 2019;10(2):e746. doi: https://doi.org/10.15649/cuidarte. v10i2.746 


\section{- Acknowledgments:}

The project was financed by the Internal Call of the University of Santander. Acta 012-14, Code PICF0114410892812EJ. It also received support from COLCIENCIAS through Call 645 of 2014 Young Researchers and Innovators and the Generación ConCiencia Program through Call No. 006. This work was carried out with the support of the Coordenação de Aperfeiçoamento de Pessoal de Nível Superior (CAPES) Brazil - Financing Code 001.

\section{- Authorsip contribution:}

Concept - Claudia Consuelo Torres Contreras.

Data selection - Astrid Nathalia Páez Esteban - Nohora

Paola Duarte Buitrago.

Formal analysis - Astrid Nathalia Páez Esteban.

Investigation - Claudia Consuelo Torres Contreras -

Astrid Nathalia Páez Esteban - Myriam Durán Parra

- Mayerli Katherine Rincón Romero - Nohora Paola

Duarte Buitrago

Methodology - Astrid Nathalia Páez Esteban.

Project management - Claudia Consuelo Torres

Contreras

Supervision - Claudia Consuelo Torres Contreras.

Writing - original draft - Claudia Consuelo Torres

Contreras - Astrid Nathalia Páez Esteban - Myriam

Durán Parra - Mayerli Katherine Rincón Romero -

Carolina Giordani da Silva - Nohora Paola Duarte

Buitrago.

Writing - review and editing - Claudia Consuelo Torres

Contreras - Astrid Nathalia Páez Esteban - Mayerli

Katherine Rincón Romero - Carolina Giordani da Silva.

The authors declare having no conflict of interest.

\section{- Corresponding author:}

Claudia Consuelo Torres Contreras

E-mail: clau.torres@mail.udes.edu.co

\section{Associate editor:}

Graziella Aliti 